\title{
Research on Applicability of the Practical Transient Voltage Stability Criterion Based on Voltage Magnitude and Sag Duration
}

\author{
Guoteng Wang, Zheng $X u$ *D and Zheren Zhang \\ College of Electrical Engineering, Zhejiang University, Hangzhou 310027, China; wgt339@zju.edu.cn (G.W.); \\ 3071001296zhang@zju.edu.cn (Z.Z.) \\ * Correspondence: xuzheng007@zju.edu.cn; Tel.: +86-0571-87952074
}

check for

updates

Citation: Wang, G.; Xu, Z.; Zhang, Z Research on Applicability of the Practical Transient Voltage Stability Criterion Based on Voltage Magnitude and Sag Duration. Appl. Sci. 2021, 11, 4569. https://doi.org/ 10.3390/app11104569

Academic Editor:

Amjad Anvari-Moghaddam

Received: 18 April 2021

Accepted: 8 May 2021

Published: 17 May 2021

Publisher's Note: MDPI stays neutral with regard to jurisdictional claims in published maps and institutional affiliations.

Copyright: (c) 2021 by the authors. Licensee MDPI, Basel, Switzerland. This article is an open access article distributed under the terms and conditions of the Creative Commons Attribution (CC BY) license (https:// creativecommons.org/licenses/by/ $4.0 /)$.

\begin{abstract}
Voltage sags threaten the transient voltage stability of power systems. To evaluate the transient voltage stability, practical criteria based on voltage magnitude and sag duration are widely used in practical engineering. However, the applicability of practical criteria needs to be studied. In this paper, in a single-load system, a theoretical derivation was first made to obtain the transient voltage stability boundary. Then, by studying the relationship between the practical criteria and the stability boundary, the application scope of the practical criteria was determined. The application scope described in this paper can guide operators to use the practical criteria correctly and avoid misjudgment of the transient voltage stability as much as possible. Finally, a case study based on PSCAD/EMTDC is presented, and the simulation results verified the conclusions proposed in this paper.
\end{abstract}

Keywords: induction motor; practical criterion; stability boundary; transient voltage stability

\section{Introduction}

With the increase of load, the transient voltage stability of a power system will deteriorate gradually [1,2]. To ensure the safe and stable operation of a large-scale power system, it is necessary to first evaluate, quickly and accurately, its transient voltage stability. Transient voltage instability usually occurs after a severe voltage sag. The primary mechanism of transient voltage instability is due to the inability of the induction motor to accelerate after disturbance or to a block of the induction motor caused by weakening of the transmission system [3-5]. Therefore, the evaluation of transient voltage stability requires evaluating the transient stability of the induction motor.

At present, there are many methods to judge transient voltage stability, including time domain simulation, the direct method, and the intelligent algorithm. Among them, the time domain simulation method is well developed and widely used in various commercial software [6]. Compared with the time domain simulation method, the direct method can avoid the heavy work of numerical integration. The most classical direct method is based on the Lyapunov theory [7,8]. In recent years, some new direct methods have been applied to transient voltage stability analysis. Ref. [9] presents a voltage stability analysis method based on the holomorphic embedding theory. Ref. [10] analyzes the transient voltage stability by stability boundaries on the power-voltage plane. However, the direct method is difficult to be applied in a large-scale power system with high orders. With the development of intelligent algorithms, the application of the intelligent algorithm has gradually attracted the attention of scholars. Data-driven intelligent algorithms have been utilized [11,12] to evaluate the transient voltage stability. However, data-driven intelligent algorithms are usually based on a large amount of accurate data, which requires a large-scale application of power management units. In some works, $[13,14]$, machine learning methods were applied to the transient voltage stability assessment. The intelligence algorithm can be 
applied to online monitoring to prevent transient voltage instability $[15,16]$. Although the intelligent algorithm has good application prospects, it is difficult to widely apply it at present, due to high complexity and large amount of calculation it involves.

The direct method and the intelligent algorithm are still far from engineering application. At present, in order to evaluate the transient voltage stability, bus voltage curves are usually obtained by the time domain simulation or the on-line monitoring first, and then a criterion is used to evaluate the voltage curves. Among various transient voltage stability criteria, there is a class of practical criteria based on voltage magnitude and sag duration that are widely used in practical engineering. For example, the technique specification of the State Grid Corporation of China (SGCC) stipulates that the voltage cannot remain below $0.8 \mathrm{pu}$ for longer than $10 \mathrm{~s}$ [17]. The reliability guideline of the Western System Coordinating Council (WSCC) establishes that the voltage drop cannot exceed $20 \%$ of the normal value for longer than $0.33 \mathrm{~s}$ [18]. In addition to practical criteria, a transient voltage stability index was proposed [19], which considers both the voltage sag and the recovery. Ref. [20] presents a method for evaluating voltage sag severity, and this method is based on the scaling and wavelet coefficient energy function. A new voltage stability index was proposed by Ratra et al. [21]. In another study [22], a voltage sag index was put forward to evaluate the severity of the voltage sag. An index was proposed to evaluate the voltage stability margin [23], and this index can be applied to the formulation of the load shedding strategy. Although a variety of criteria have been proposed, the widely used transient voltage stability criteria in practical engineering are still the practical criteria based on voltage magnitude and sag duration. The practical criteria are used as reliability guidelines in many power grids because they are convenient and practical. However, the accepted duration of voltage drop by the SGCC $(10 \mathrm{~s})$ is quite different from that of the WSCC $(0.33 \mathrm{~s})$. This difference is so large that it cannot be attributed to grid data. This difference also brings confusion to power grid operators, about which practical criterion should be used. At present, there is no public literature to explain the difference between the two practical criteria, and the application scope of the two practical criteria has not been discussed.

In this paper, we studied the application scope of the practical criteria. Our conclusions can help power grid operators to use the practical criteria correctly and avoid misjudgment. The remainder of this paper is organized as follows. The system model is introduced in Section 2. The transient voltage stability boundary is derived in Section 3. Section 4 gives the application scope of the practical criteria. A simulation is carried out in Section 5, and the conclusions are drawn in Section 6.

\section{Model Description}

Induction motor stalling is the leading cause of voltage collapse in a radiation system [24]. Therefore, a single-load system was chosen in this paper, as Figure 1a shows. In Figure 1a, the induction motor is connected to a low-voltage bus 4, while the practical criterion is used for the voltage curve of the high-voltage bus 1 .

The equivalent circuit of a single-load system in which the equivalent capacitances of the branches and the transformers are ignored is shown in Figure $1 \mathrm{~b}$. In Figure $1 \mathrm{~b}, R_{l}$ is the branch resistance, $X_{l}$ is the branch reactance, $R_{s}$ is the stator resistance, $X_{s}$ is the stator reactance, $X_{m}$ is the excitation reactance of the motor, $X_{r}$ is the rotor reactance, $R_{r}$ is the rotor resistance, $s$ is the slip.

In this paper, the first-order model is adopted for the induction motor, and the rotor motion equation of the induction motor is shown as Equation (1)

$$
2 H \frac{d s}{d t}=T_{l}(s)-T_{e}\left(U_{1}, s\right)
$$

Here, $H$ is the rotor inertia constant, $T_{l}$ is the load torque, $T_{e}$ is the electromagnetic torque, $U_{1}$ is the bus 1 voltage. 


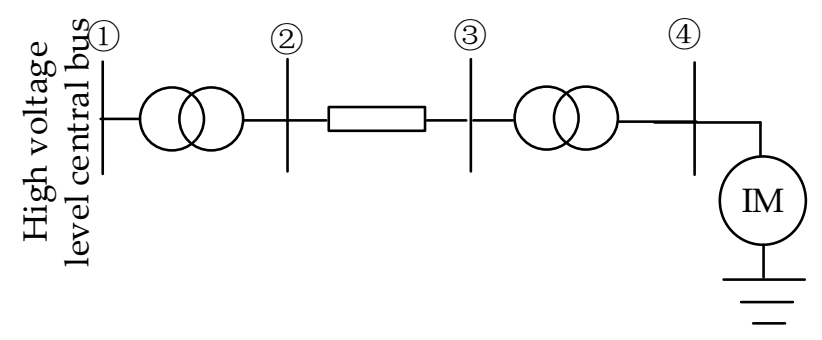

(a)

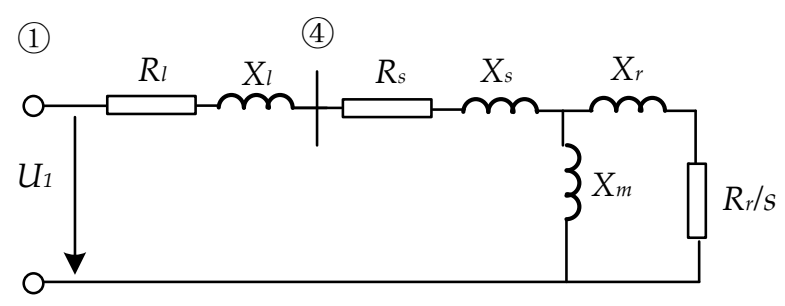

(b)

Figure 1. Single-load system: (a) structure of the single-load system; (b) equivalent circuit of the single-load system.

The electromagnetic torque of the induction motor is Equation (2).

$$
T_{e}\left(U_{1}, s\right)=\frac{Z_{e q}^{2} U_{1}^{2} \frac{R_{r}}{s}}{\left(R_{e q}+\frac{R_{r}}{s}\right)^{2}+\left(X_{e q}+X_{r}\right)^{2}}
$$

Here,

$$
R_{e q}+j X_{e q}=\frac{j X_{m}\left(R_{s}+R_{l}+j X_{s}+j X_{l}\right)}{R_{s}+R_{l}+j\left(X_{s}+X_{l}+X_{m}\right)}, Z_{e q}=\frac{X_{m}}{\sqrt{\left(R_{s}+R_{l}\right)^{2}+\left(X_{s}+X_{m}+X_{l}\right)^{2}}}
$$

There are mainly three kinds of load: the constant torque load, the constant power load, and the fan-pump load. The load torques are as follows.

Constant torque load shown as Equation (3).

$$
T_{l, \text { ConT }}(s)=T_{0}
$$

Constant power load shown as Equation (4).

$$
T_{l, \operatorname{ConP}}(s)=T_{0}+P_{0} /(1-s)
$$

Fan-pump load shown as Equation (5).

$$
T_{l, \text { Fan }}(s)=T_{0}+T_{1}(1-s)^{2}
$$

Here, $T_{0}, T_{1}$, and $P_{0}$ are constant parameters.

\section{Transient Voltage Stability Boundary}

This section may be divided by subheadings. The goal is to provide a concise and precise description of the experimental results, their interpretation, as well as the experimental conclusions that can be drawn.

In order to study the applicability of the practical criteria, the transient voltage stability boundary needs to be derived firstly. To facilitate the theoretical derivation, the following assumptions were made: 
(1) Simplify the voltage curve of bus 1, as Figure 2 shows. The voltage magnitude was initially $U_{0}$, it dropped to $U_{\text {sag }}$ during the fault, and then was restored to $U_{r e}$ after fault clearance. The voltage sag lasted for $t_{s a g}$.

(2) The power system was considered unstable if the induction motor stalled, and the system was stable if the induction motor did not stall.

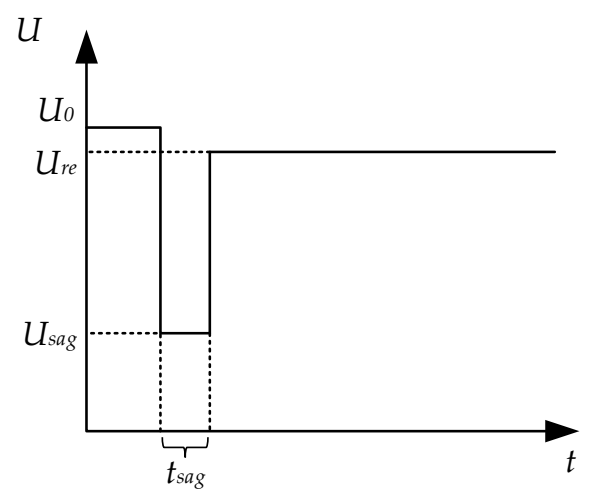

Figure 2. Simplified voltage sag waveform.

Based on the above assumptions, the voltage stability boundary of the induction motor can be derived. Before deducing the voltage stability boundary, we first introduce two crucial parameters, namely, the safe voltage magnitude and the safe sag duration.

\subsection{Safe Voltage Magnitude}

There exists a safe voltage magnitude $U_{\text {safe }}$ for $U_{\text {sag. }}$. During voltage sag, as long as $U_{\text {sag }}$ is higher than $U_{\text {safe, }}$, the induction motor will not stall, no matter how long the voltage sag lasts [2].

In Figure 3a, curve 1 is the electromagnetic torque curve of the induction motor under rated voltage, and the induction motor operates at point A initially. When the bus voltage drops slightly, the electromagnetic torque curve becomes curve 2, and the operating point of the induction motor is changed from A to A1. Even if the voltage is not restored to the initial value, the induction motor can operate stably. However, if the bus voltage drops sharply, there is no intersection between the electromagnetic torque curve and the load torque curve, and the slip of the induction motor will increase until the induction motor is stalled, as curve 3 shows.

With the decrease of the bus voltage, the number of intersections between the electromagnetic torque curve and the load torque curve changed from two to one, and finally to zero. When there is only one intersection between the electromagnetic torque curve and the load torque curve, the bus voltage magnitude is the safe voltage magnitude $U_{\text {safe }}$. As long as $U_{\text {sag }}$ is higher than $U_{\text {safe }}$, the motor will not stall, no matter how long the voltage sag lasts. At the safe voltage magnitude, the intersection is located at the point with the maximum electromagnetic torque, and the slip at this point is $s_{m}$, as Equation (6) shows. Equation (7) can be obtained when the slip $s$ equals $s_{m}$.

$$
\begin{gathered}
T_{l}\left(s_{m}\right)=T_{e}\left(U_{s a f e}, s_{m}\right) \\
\left.\frac{d T_{e}(U, s)}{d s}\right|_{s=s_{m}}=0
\end{gathered}
$$


According to Equations (2) and (7), the expression of $s_{m}$ can be obtained as Equation (8). The value of $s_{m}$ has nothing to do with the voltage magnitude, $s_{m}$ remains unchanged when the bus voltage magnitude changes.

$$
s_{m}=\frac{R_{r}}{\sqrt{\left(R_{s}+R_{l}\right)^{2}+\left(X_{s}+X_{l}+X_{r}\right)^{2}}}
$$

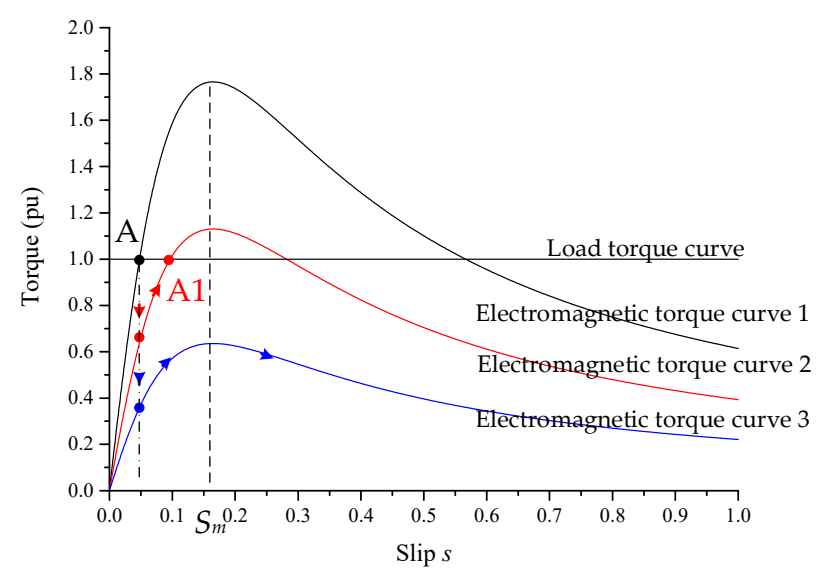

(a)

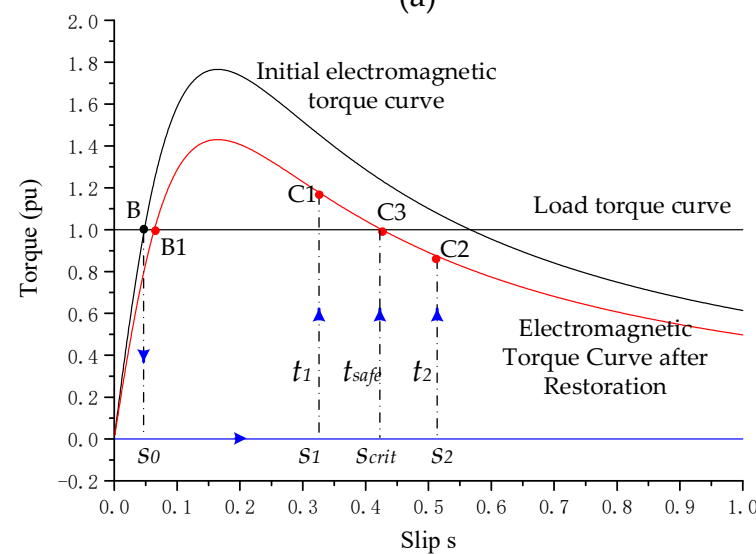

(b)

Figure 3. Diagrams illustrating two crucial parameters: (a) safe voltage magnitude; (b) te safe sag duration.

In general, the excitation reactance of the induction motor is relatively large. To facilitate a theoretical derivation, the excitation can be approximated to that of an open circuit, and the constant torque load can be adopted. Then, the expression of $U_{\text {safe }}$ can be obtained as Equation (9), according to Equations (6)-(8).

$$
U_{\text {safe }}=\sqrt{2 R_{t} T_{0}+2 T_{0} \sqrt{R_{t}^{2}+X_{t}^{2}}}
$$

Here,

$$
R_{t}=R_{l}+R_{s}, X_{t}=X_{l}+X_{s}+X_{r}
$$

From (9), it can be concluded that the safe voltage magnitude $U_{\text {safe }}$ has nothing to do with the rotor resistance and the rotor inertia constant. The increase of the stator impedance, the branch impedance, the rotor reactance, or the load torque will increase the safe voltage magnitude, which is detrimental to the transient voltage stability. 


\subsection{Safe Sag Duration}

Assuming that $U_{\text {sag }}$ is zero during voltage sag, then the electromagnetic torque of the induction motor is zero. In this case, the increasing speed of the slip is the highest. When $U_{s a g}$ is zero, the sag duration that causes a critical instability of the induction motor is called the safe sag duration $t_{\text {safe }}$ [3]. As Figure $3 \mathrm{~b}$ shows, the induction motor initially operates at point $\mathrm{B}$. When the bus voltage drops to zero, the slip of the induction motor increases rapidly. If the voltage sag duration is $t_{1}$, the induction motor operates at point $\mathrm{C} 1$ at the moment of voltage recovery. Then, the slip will decrease, and the motor finally operates at point B1 stably. If the voltage sag duration is $t_{2}$, the induction motor operates at point $\mathrm{C} 2$ at the moment of voltage recovery. Then, the slip will continue to increase, and the motor will stall. If the voltage sag duration is $t_{\text {safe, }}$, the induction motor is critically stable. The safe sag duration $t_{\text {safe }}$ is the critical sag duration when $U_{\text {sag }}$ is zero. As long as $t_{\text {sag }}$ is less than $t_{\text {safe }}$, the induction motor can remain stable, independently of the value of $U_{\text {sag }}$. Equation (10) can be obtained according to Equation (2). The meaning of Equation (10) is that when the voltage drops to $U_{\text {sag }}$, the time required for the slip to increase from $s_{0}$ to $s_{n}$ is $t_{n}$. Equation (11) can be obtained according to Equation (10):

$$
\begin{gathered}
t_{n}=\int_{s_{0}}^{s_{n}} \frac{2 H}{T_{l}(s)-T_{\mathcal{e}}\left(U_{\text {sag }}, s\right)} d s \\
t_{\text {safe }}=\int_{s_{0}}^{s_{\text {crit }}} \frac{2 H}{T_{l}(s)} d s
\end{gathered}
$$

In Figure 2, assuming that $U_{r e}$ is equal to $U_{0}, s_{c r i t}$ can be obtained by equalizing the load torque and the electromagnetic torque (Equation (12)):

$$
T_{l}(s)=T_{e}\left(U_{0}, s\right)
$$

In Equation (12), only the slip $s$ is unknown. Two solutions can be obtained by solving Equation (12): the larger value corresponds to $s_{\text {crit }}$, and the smaller one is $s_{0}$. Combining Equations (11)-(12), the expression of $t_{\text {safe }}$ is obtained as Equation (13).

$$
t_{\text {safe }}=\frac{2 H R_{r}}{T_{0}^{2}} \frac{\sqrt{U_{0}^{4}-4 R_{t} U_{0}^{2} T_{0}-4 X_{t}^{2} T_{0}^{2}}}{\left(R_{t}^{2}+X_{t}^{2}\right)}
$$

It can be concluded from Equation (13) that the increase of stator impedance, branch impedance, rotor reactance, or load torque will reduce $t_{\text {safe }}$, which is detrimental to the transient voltage stability. The increase of the rotor resistance or the rotor inertia constant will increase the safe sag duration, which is beneficial to the transient voltage stability.

\subsection{Stability Boundary Based on Voltage Magnitude and Sag Duration}

As can be seen from Figure $3 \mathrm{~b}$, if the slip $s$ exceeds $s_{\text {crit }}$ during the voltage sag, the induction motor will stall. Assuming that the critical sag duration is $t_{c r i t}$ when the voltage drops to $U_{s a g}$, the induction motor will remain stable if the sag duration $t_{\text {sag }}$ is less than $t_{c r i t}$, and the motor will stall if $t_{\text {sag }}$ is larger than $t_{c r i t}$. The expression of $t_{c r i t}$ is Equation (14).

$$
t_{c r i t}=\int_{s_{0}}^{s_{c r i t}} \frac{2 H}{T_{l}(s)-T_{e}\left(U_{s a g}, s\right)} d s
$$

On the $U-t$ plane, the transient voltage stability boundary is drawn, as Figure 4 shows. The stability boundary is the curve of $t_{\text {crit }}$ versus $U_{\text {sag. }}$. The voltage magnitude $U_{\text {sag }}$ and the sag duration $t_{\text {sag }}$ can be used to determine a point $\left(t_{\text {sag }}, U_{\text {sag }}\right)$ on the $U-t$ plane. If the point is located in the region above the stability boundary, the induction motor can operate stably. On the contrary, if the point is located in the region below the stability boundary, the induction motor will stall. As Figure 4 shows, the stability boundary starts from point $\left(t_{\text {safe }}, 0\right)$ and approaches $U_{\text {safe }}$ infinitely with the increase of $t_{\text {sag. }}$. 


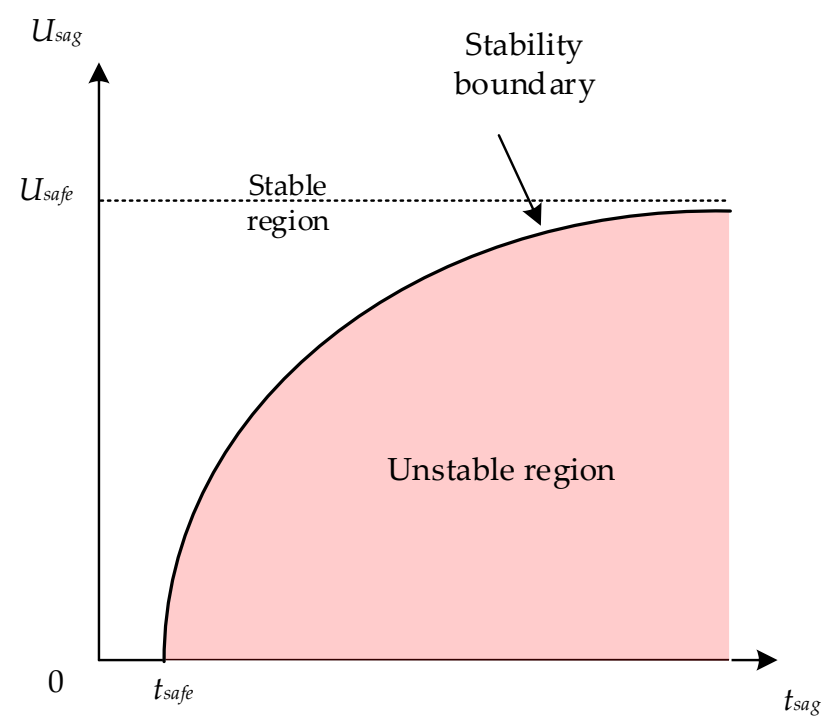

Figure 4. Diagram of the transient voltage stability boundary.

\section{Applicability of the Practical Criterion}

In this section, the influence of system parameters on the stability boundary is analyzed, and the applicability of the practical criteria is studied.

\subsection{System Parameters Analysis}

In the following, the typical parameters of the large industrial motor were adopted [2]. The parameters of the single-load system are shown in Table 1 . The load model was the constant torque load, and the load rate was $50 \%$. The load rate is the ratio of the load torque to the maximum electromagnetic torque.

Table 1. Parameters of the single-load system.

\begin{tabular}{ccccccccc}
\hline Item & $\boldsymbol{R}_{s} / \mathbf{p u}$ & $\boldsymbol{X}_{s} / \mathrm{pu}$ & $\boldsymbol{X}_{\boldsymbol{m}} / \mathbf{p u}$ & $\boldsymbol{R}_{r} / \mathrm{pu}$ & $\boldsymbol{X}_{\boldsymbol{r}} / \mathrm{pu}$ & $\boldsymbol{H} / \mathbf{s}$ & $\boldsymbol{R}_{l} / \mathrm{pu}$ & $X_{l} / \mathrm{pu}$ \\
\hline Value & 0.007 & 0.041 & 3.62 & 0.0062 & 0.0267 & 1.6 & 0.015 & 0.1 \\
\hline
\end{tabular}

Firstly, the influence of the stator reactance on the stability boundary was analyzed. Based on the parameters in Table 1, we changed the stator reactance value to $0.02 \mathrm{pu}$, $0.041 \mathrm{pu}$, and $0.082 \mathrm{pu}$, respectively. Three transient voltage stability boundaries under different stator reactance are plotted in Figure 5a. As can be seen from Figure 5a, the larger the stator reactance, the larger the unstable region. The increase of the stator reactance will increase the safe voltage magnitude and reduce the safe sag duration, which is not conducive to the stable operation of the motor. Besides, the influence of the rotor reactance on the stability boundary is the same as that of the stator reactance, as Figure $5 b$ shows.

Then, the influence of the rotor resistance on the stability boundary was analyzed. Similarly, three values of the rotor resistance were selected, i.e., $0.0031 \mathrm{pu}, 0.0062 \mathrm{pu}$, and $0.0124 \mathrm{pu}$. Three transient voltage stability boundaries under different rotor resistance were plotted, as Figure $5 \mathrm{c}$ shows. It can be seen from Figure $5 \mathrm{c}$ that the larger the rotor resistance, the smaller the unstable region. The increase of the rotor resistance will increase the safe sag duration, which is beneficial to the stability of the motor. Besides, the rotor resistance has no effect on the safe voltage magnitude.

Finally, the influence of the load rate on the stability boundary was analyzed. The load rate was $30 \%, 50 \%$, and $80 \%$ to represent the three operation conditions of light load, normal load, and heavy load. The stability boundaries for the three load rates are plotted in Figure 5d. It can be seen from Figure 5d that the unstable region expands rapidly with the increase of the load rate. The values of the safe voltage magnitude and the safe sag duration vary greatly under the three load rates. 


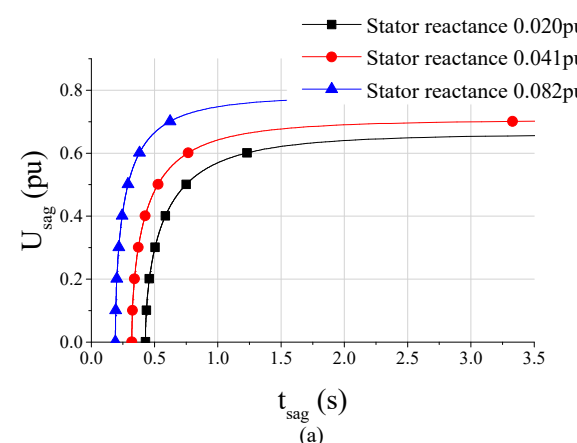

(a)
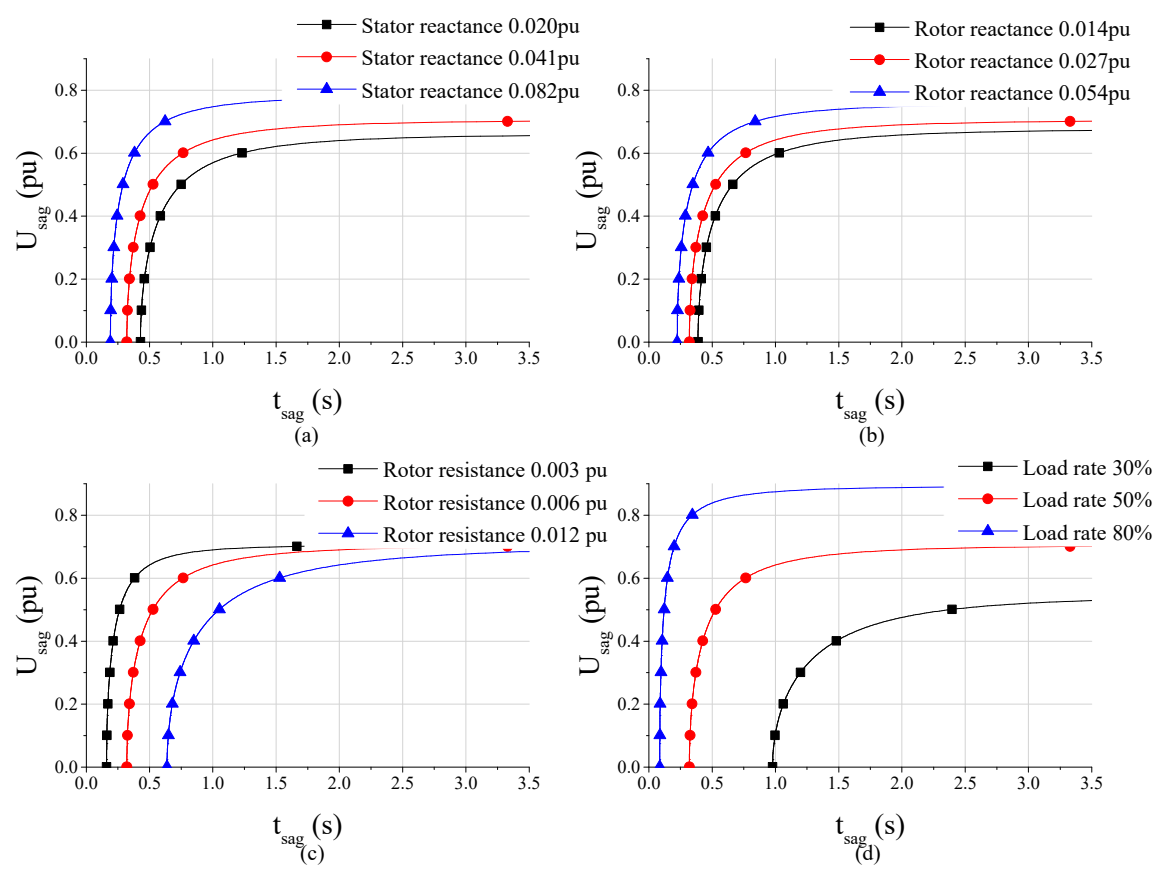

Figure 5. Transient voltage stability boundaries: (a) transient voltage stability boundaries for different values of stator reactance; (b) transient voltage stability boundaries for different values of rotor reactance; (c) transient voltage stability boundaries for different values of rotor resistance; (d) Transient voltage stability boundaries for different load rates.

\subsection{Influence of Low-Voltage Protection}

In the above discussion, the low-voltage protection link of the motor was not considered. Most industrial motors are equipped with a low-voltage protection. The low-voltage protection is usually achieved by electromechanical AC contactors. If the bus voltage is lower than a certain threshold, such contactors trip immediately and cut off the power supply of the motor. The tripping voltage $U_{\text {trip }}$ of the contactor was about $0.3 \sim 0.7 \mathrm{pu}$. When the bus voltage is lower than $U_{\text {trip }}$, the motor is cut off to prevent transient voltage instability. Therefore, the unstable region of the motor will change after considering the low voltage protection, as Figure 6 shows. If the low-voltage protection is activated, the induction motor is removed, and the motor will not stall. Therefore, in the following discussion, $U_{\text {sag }}$ was chosen to be greater than $U_{\text {trip }}$.

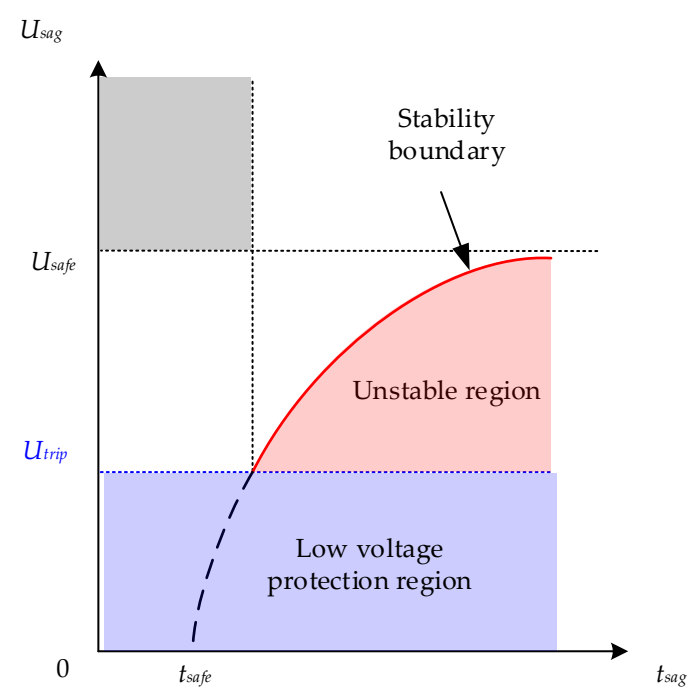

Figure 6. Unstable region considering low-voltage protection. 


\subsection{Application Scope of the Practical Criteria}

According to the results shown in Figure 5, when the voltage drops seriously, the motor will become unstable only for a short sag duration. When the voltage drops slightly, a long sag duration is needed to cause motor instability. This shows that the practical criteria cannot give an accurate judgment in all situations. Therefore, the application scope of the practical criterion needs to be discussed.

We assumed that the practical criterion was that the voltage could not be lower than $U_{\mathrm{s}}$ for a time exceeding $T_{\mathrm{s}}$. The voltage magnitude $U_{\mathrm{s}}$ and the duration $T_{\mathrm{s}}$ form a point $\left(T_{\mathrm{s}}, U_{\mathrm{s}}\right)$ in Figure 6. The application scope of the practical criterion varies with the location of the point, as indicated below.

(1) If point $\left(U_{\mathrm{s}}, T_{\mathrm{s}}\right)$ falls in the red region, the system can be determined to be unstable when the voltage drops below $U_{\mathrm{s}}$ and remains low for longer than $T_{\mathrm{s}}$.

(2) If point $\left(U_{\mathrm{s}}, T_{\mathrm{s}}\right)$ falls in the grey region, the system can be determined to be stable when the voltage is larger than $U_{\mathrm{s}}$ or the sag duration is less than $T_{\mathrm{s}}$.

(3) If point $\left(U_{\mathrm{s}}, T_{\mathrm{s}}\right)$ falls in the white region, the stability cannot be determined only by the voltage magnitude $U_{\mathrm{s}}$ and the duration $T_{\mathrm{s}}$.

The WSCC stipulates that the voltage cannot remain below $0.8 \mathrm{pu}$ for longer than $0.33 \mathrm{~s}$. In China, the SGCC stipulates that the voltage magnitude shall not be lower than $0.8 \mathrm{pu}$ for more than $10 \mathrm{~s}$. Comparing the two practical criteria with the stability boundaries in Figure 5, we can draw the following conclusions:

(1) It can be approximately considered that the system will be stable if the voltage is higher than $0.8 \mathrm{pu}$ or the sag duration is less than $0.33 \mathrm{~s}$.

(2) It can be approximately considered that the system will be unstable if the voltage drops below $0.8 \mathrm{pu}$ and remains low for more than $10 \mathrm{~s}$.

(3) If the voltage drops below $0.8 \mathrm{pu}$ and remains low for $0.33-10 \mathrm{~s}$, the system stability cannot be determined.

Obviously, the three conclusions are not applicable to all power systems and all working conditions. However, the goal of this paper is mainly to clarify the applicability of the practical criteria. The specific values of voltage magnitude and sag duration are obtained by engineers through their experience. Therefore, the above conclusions can still be applied in practical engineering.

\section{Case Study}

In this section, we will verify the application scope of the practical criteria through simulation; the simulation software used was PSCAD/EMTDC. The verifying case study was based on the power system model of the Chuxiong region in China. The grid structure of the system is shown in Figure 7. In the power grid of the Chuxiong region, the load is mainly connected with five buses, including the Yuanmou bus, the Chuqian bus, the Xiejiahe bus, the Nanhua bus, and the Pupeng bus. The load model is the integrated load model, which is equivalent to a distribution power system. The integrated load model includes the transmission branch, the industrial induction motor, and a constant impedance. The proportion of the industrial induction motor load is 70\%. In PSCAD/EMTDC, the wound rotor induction machine model was adopted to simulate industrial induction. The parameters of the system are shown in Tables 2 and 3. Besides, the practical criteria were used for the Lucheng bus voltage. 


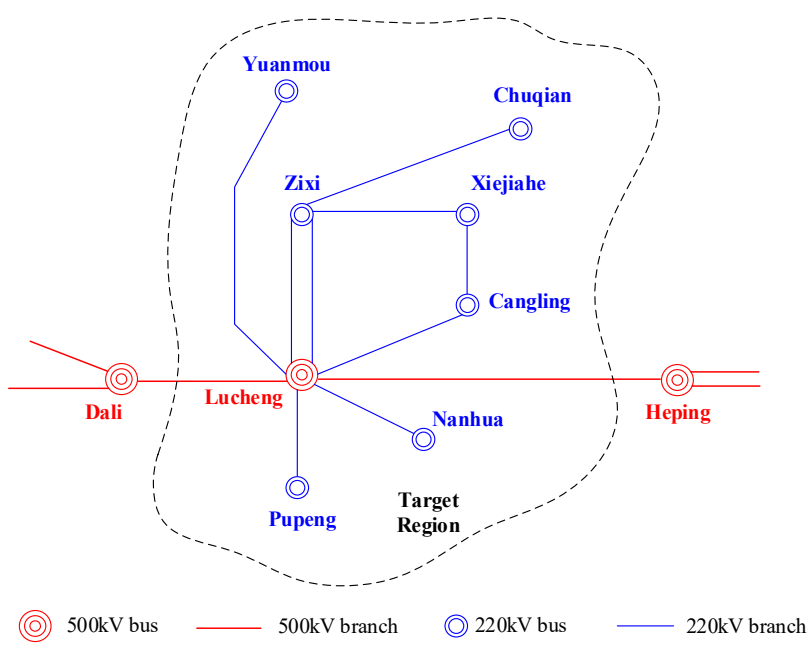

Figure 7. Single-line diagram of the Chuxiong region power grid.

Table 2. Parameters of the loads.

\begin{tabular}{cc}
\hline Bus & Value (MW) \\
\hline Yuanmou & 15 \\
\hline Chuqian & 22 \\
\hline Xiejiahe & 11 \\
\hline Nanhua & 63 \\
\hline
\end{tabular}

Table 3. Parameters of the induction motor.

\begin{tabular}{cc}
\hline Item & Value (pu) \\
\hline Stator resistance $R_{\mathrm{a}}$ & 0.007 \\
\hline Stator reactance $X_{\mathrm{a}}$ & 0.0818 \\
\hline Excitation reactance $X_{\mathrm{m}}$ & 3.62 \\
\hline Rotor resistance $R_{\mathrm{r}}$ & 0.0062 \\
\hline Rotor reactance $X_{\mathrm{r}}$ & 0.0534 \\
\hline Rotor inertia time constant $H$ & 1.6 \\
\hline
\end{tabular}

\subsection{Validation of the WSCC Practical Criterion}

As mentioned in Section 4, the system can be judged to be stable if the bus voltage is higher than $0.8 \mathrm{pu}$ or the voltage sag duration is less than $0.33 \mathrm{~s}$. On the contrary, if the voltage drops below $0.8 \mathrm{pu}$ and remains low for more than $0.33 \mathrm{~s}$, the system cannot be judged as unstable. These conclusions will be verified below.

Firstly, the conclusion that the system will be stable if the bus voltage is higher than $0.8 \mathrm{pu}$ was verified. A permanent short-circuit fault was applied to the Lucheng bus, and the Lucheng bus voltage dropped to $0.8 \mathrm{pu}$. The voltage no longer recovered. The Lucheng bus voltage curve is shown in Figure 8a, and the slip curves of the induction motors are shown in Figure $8 \mathrm{~b}$. As can be seen from Figure 8b, the induction motors operated at a new steady-state point after the Lucheng bus voltage dropped to $0.8 \mathrm{pu}$. This shows that the induction motors would not stall as long as the Lucheng bus voltage was higher than $0.8 \mathrm{pu}$.

Then, the conclusion that the system will be stable if the voltage sag duration is less than $0.33 \mathrm{~s}$ was verified. In the Chuxiong region, if the bus voltage is less than $0.5 \mathrm{pu}$, the low voltage protection device will act to cut off the induction motor. Therefore, the lowest bus 
voltage that may cause motor stalling is $0.5 \mathrm{pu}$. A short-circuit fault was applied to the Lucheng bus, the fault lasted for $0.33 \mathrm{~s}$, and the Lucheng bus voltage dropped to $0.5 \mathrm{pu}$ during the fault. The bus voltage curve is shown in Figure $8 \mathrm{c}$, and the slip curves are shown in Figure $8 \mathrm{~d}$. As can be seen from Figure $8 \mathrm{~d}$, the induction motors would not stall if the bus voltage dropped to $0.5 \mathrm{pu}$ and remained low for $0.33 \mathrm{~s}$. Therefore, it can be considered that the system will be stable if the voltage sag duration is less than $0.33 \mathrm{~s}$.

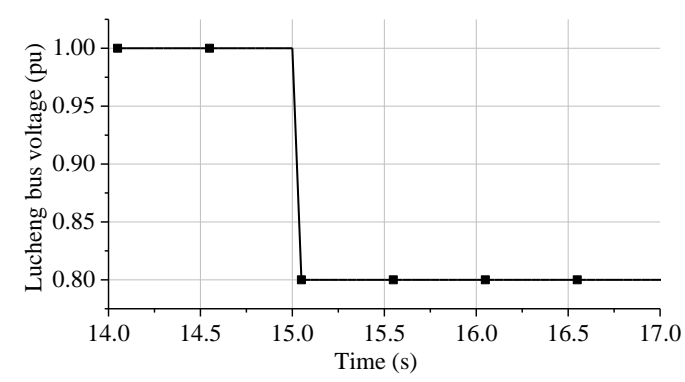

(a)

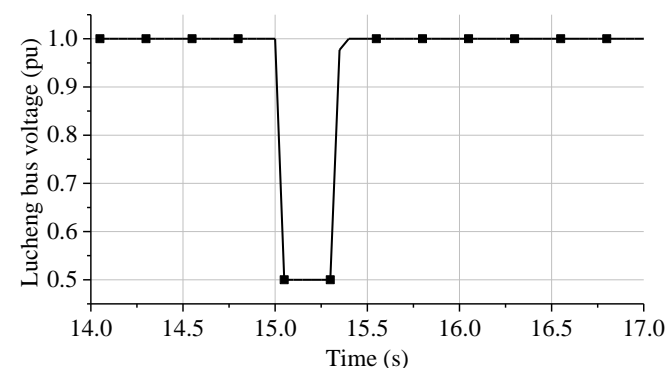

(c)

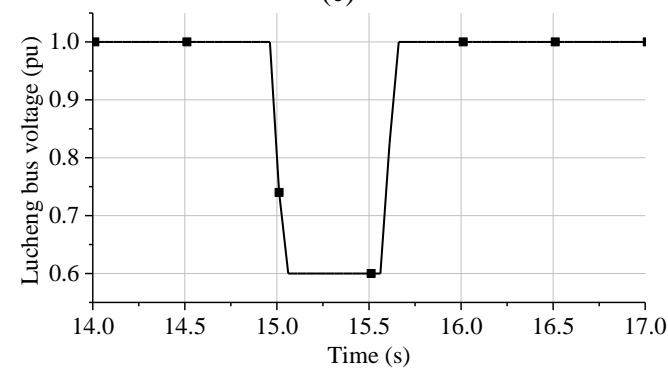

(e)

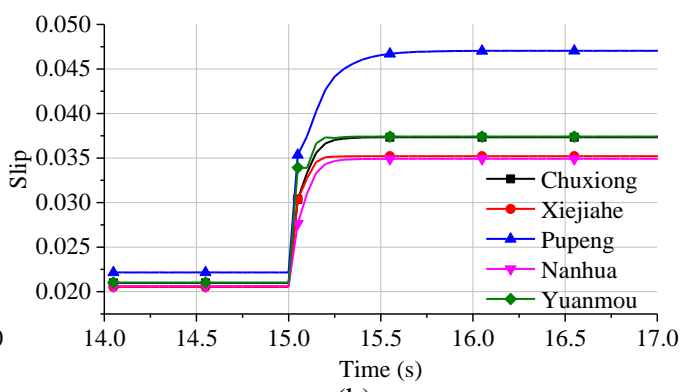

(b)

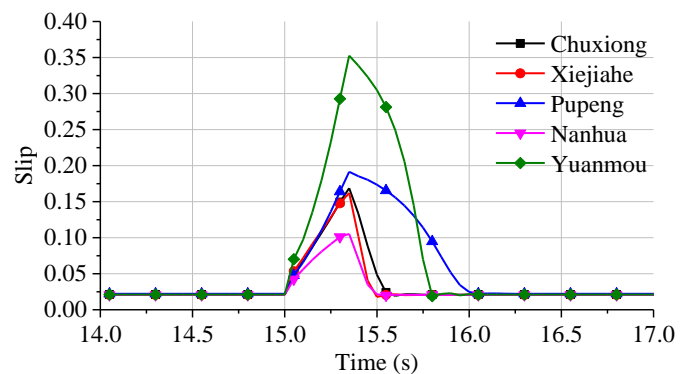

(d)

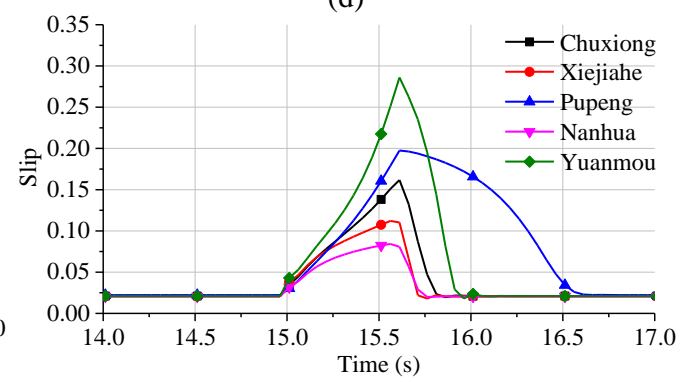

(f)

Figure 8. Simulation results to verify the WSCC practical criterion: (a) Lucheng bus voltage curve (condition 1), (b) motor slip curves (condition 1); (c) Lucheng bus voltage curve (condition 2); (d) motor slip curves (condition 2); (e) Lucheng bus voltage curve (condition 3); (f) motor slip curves (condition 3).

Finally, the conclusion that the system cannot be determined to be unstable if the bus voltage drops below $0.8 \mathrm{pu}$ and remains low for more than $0.33 \mathrm{~s}$ was verified. Similarly, a short-circuit fault was applied to the Lucheng bus, the bus voltage dropped to $0.6 \mathrm{pu}$, and the sag lasted for $0.6 \mathrm{~s}$. The voltage curve is shown in Figure 8e, and the slip curves are shown in Figure 8f. Obviously, the voltage dropped below $0.8 \mathrm{pu}$ and remained low for more than $0.33 \mathrm{~s}$. However, the induction motors could still return to the original steadystate point after fault clearance. Therefore, the system cannot be judged to be unstable if the voltage drops below $0.8 \mathrm{pu}$ and remains low for more than $0.33 \mathrm{~s}$.

\subsection{Validation of the SGCC Practical Criterion}

Next, the practical criterion of the SGCC was verified. As mentioned in Section 4, the system can be judged to be unstable if the bus voltage drops below $0.8 \mathrm{pu}$ and remains low for more than $10 \mathrm{~s}$. To verify this conclusion, a short-circuit fault was applied to the Lucheng bus, the Lucheng bus voltage dropped to $0.7 \mathrm{pu}$, and the fault lasted for $10 \mathrm{~s}$, as Figure 9a shows. The slip curves of the induction motors are shown in Figure 9b. 
As can be seen from Figure 9b, the motor connected with the Pupeng bus stalled. In fact, the Chuxiong power grid has the possibility of instability only when the Lucheng bus voltage is lower than $0.73 \mathrm{pu}$. To be exact, the Chuxiong power grid is unstable if the bus voltage drops below $0.73 \mathrm{pu}$ and remains low for more than $10 \mathrm{~s}$. However, a certain stability margin is usually reserved in practical engineering. Therefore, the conclusion that the system can be judged as unstable if the voltage drops below $0.8 \mathrm{pu}$ and remains low for more than $10 \mathrm{~s}$ is considered reasonable.

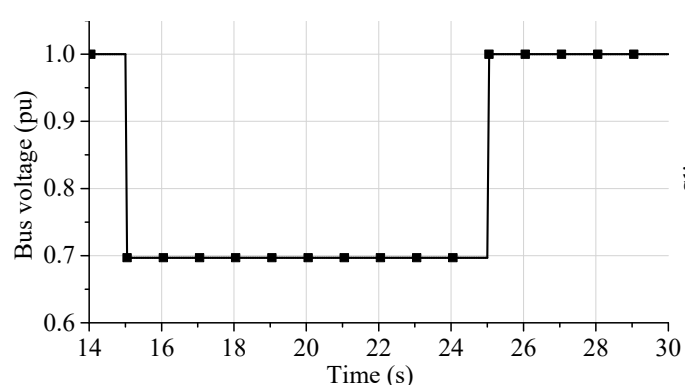

(a)

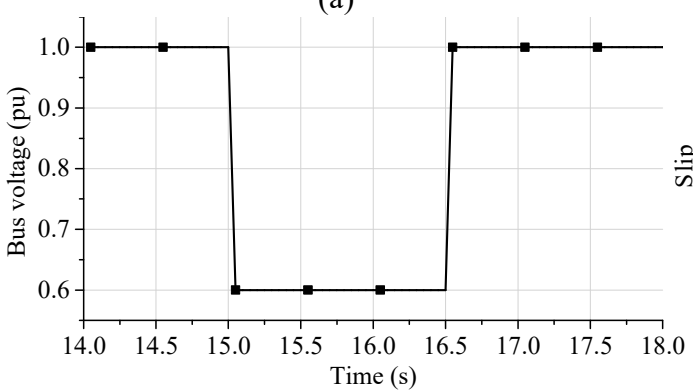

(c)

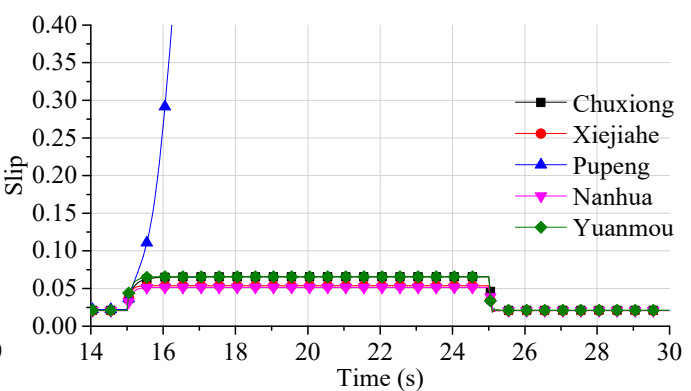

(b)

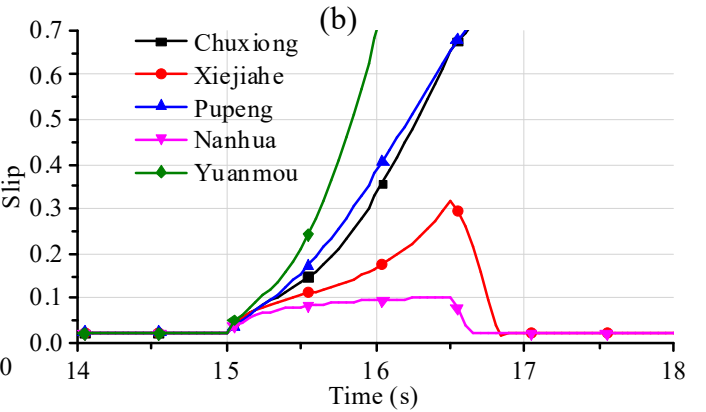

(d)

Figure 9. Simulation results to verify the SGCC practical criterion: (a) Lucheng bus voltage curve (condition 1); (b) motor slip curves (condition 1); (c) Lucheng bus voltage curve (condition 2); (d) motor slip curves (condition 2).

On the contrary, if the voltage remains lower than 0.8 pu for less than $10 \mathrm{~s}$, the system cannot be judged to be stable. As Figure 9c shows, the Lucheng bus voltage dropped to $0.6 \mathrm{pu}$ and remained low for $1.5 \mathrm{~s}$. Under this disturbance, the slip curves of the induction motors are shown in Figure $9 d$. According to Figure $9 c, d$, the system may be unstable even if the voltage sag duration is less than $10 \mathrm{~s}$.

\section{Conclusions}

In this paper, the transient voltage stability boundary based on voltage magnitude and sag duration was deduced theoretically. By comparing the practical transient voltage stability criteria with the stability boundary, the application scope of the practical criteria was proposed in this paper. At present, the two most widely used criteria are formulated by the WSCC and the SGCC. The WSCC stipulates that the voltage cannot be below $0.8 \mathrm{pu}$ for longer than $0.33 \mathrm{~s}$. In China, the SGCC stipulates that the voltage magnitude shall not be lower than $0.8 \mathrm{pu}$ for more than $10 \mathrm{~s}$. In order to prove the applicability of the two criteria, we first theoretically derived the transient voltage stability boundary based on voltage magnitude and sag duration. According to the theoretical results, the two practical criteria mentioned above are not the sufficient and necessary conditions for transient voltage stability. However, in most systems with typical parameters, the practical criterion of the WSCC can be approximately considered as a sufficient condition for transient voltage stability, and the practical criterion of the SGCC can be approximately considered as a necessary condition for transient voltage stability. Through simulation in an actual power system, the theoretical results were verified. 
Author Contributions: G.W.: Conceptualization, Methodology, Software, Visualization, WritingOriginal Draft, Formal analysis. Z.X.: Supervision, Project administration, Resources, Data curation, Writing-Review \& Editing. Z.Z.: Validation, Investigation. All authors have read and agreed to the published version of the manuscript.

Funding: This research received no external funding.

Institutional Review Board Statement: Not applicable.

Informed Consent Statement: Not applicable.

Data Availability Statement: The data presented in this study are available on request from the corresponding author. The data are not publicly available due to commercial requirements.

Conflicts of Interest: The authors declare no conflict of interest.

\section{References}

1. Xue, Y.; Xu, T.; Liu, B.; Li, Y. Quantitative assessments for transient voltage security. IEEE Trans. Power Syst. 2000, 15, 1077-1083. [CrossRef]

2. Kundur, P. Power System Stability and Control; EPRI Power System Engineering Series; McGraw Hill: New York, NY, USA, 1994.

3. CIGRE Task Force 38.02.10. Criteria and Countermeasures for Voltage Collapse; CIGRE: Paris, France, 1995.

4. CIGRE Working Group 34.08. Protection against Voltage Collapse; Karlsson, D., Ed.; CIGRE: Paris, France, 1998.

5. CIGRE Task Force 38.02.10. Cigre Technical Brochure: Modeling of Voltage Collapse Including Dynamic Phenomena; ELECTR No.147; CIGRE: Paris, France, 1993.

6. Power Technologies Inc. PSS/E Application Manual and Operation Manual, PSS/E Brochure; Power Technologies Inc.: Monroe Township, NJ, USA, 2001.

7. Bosetti, H.; Khan, S. Transient Stability in Oscillating Multi-Machine Systems Using Lyapunov Vectors. IEEE Trans. Power Syst. 2018, 33, 2078-2086. [CrossRef]

8. Vu, T.L.; Turitsyn, K. Lyapunov Functions Family Approach to Transient Stability Assessment. IEEE Trans. Power Syst. 2016, 31, 1269-1277. [CrossRef]

9. Yao, R.; Sun, K.; Shi, D.; Zhang, X. Voltage Stability Analysis of Power Systems with Induction Motors Based on Holomorphic Embedding. IEEE Trans. Power Syst. 2018, 34, 1278-1288. [CrossRef]

10. Kawabe, K.; Tanaka, K. Analytical Method for Short-Term Voltage Stability Using the Stability Boundary in the P-V Plane. IEEE Trans. Power Syst. 2014, 29, 3041-3047. [CrossRef]

11. Zhang, Y.; Xu, Y.; Zhang, R.; Dong, Z.Y. A Missing-Data Tolerant Method for Data-Driven Short-Term Voltage Stability Assessment of Power Systems. IEEE Trans. Smart Grid 2018, 10, 5663-5674. [CrossRef]

12. Ge, H.; Guo, Q.; Sun, H.; Zhao, W. A model and data hybrid-driven short-term voltage stability real-time monitoring method. Int. J. Electr. Power Energy Syst. 2020, 114, 105373. [CrossRef]

13. Liao, H.; Milanovic, J.V.; Rodrigues, M.; Shenfield, A. Voltage Sag Estimation in Sparsely Monitored Power Systems Based on Deep Learning and System Area Mapping. IEEE Trans. Power Deliv. 2018, 33, 3162-3172. [CrossRef]

14. Zhu, L.; Lu, C.; Liu, Y.; Wu, W.; Hong, C. Wordbook-based light-duty time series learning machine for short-term voltage stability assessment. IET Gener. Transm. Distrib. 2017, 11, 4492-4499. [CrossRef]

15. Goh, H.; Chua, Q.; Lee, S.; Kok, B.; Goh, K.; Teo, K. Evaluation for Voltage Stability Indices in Power System Using Artificial Neural Network. Procedia Eng. 2015, 118, 1127-1136. [CrossRef]

16. Yu, J.J.Q.; Hill, D.J.; Lam, A.Y.S.; Gu, J.; Li, V.O.K. Intelligent Time-Adaptive Transient Stability Assessment System. IEEE Trans. Power Syst. 2018, 33, 1049-1058. [CrossRef]

17. Q/GDW 1404-2015. The Standard on Power System Simulation for Security and Stability; State Grid: Beijing, China, 2015. (In Chinese)

18. NERC/WECC: 'Planning Standards'. 2003. Available online: https://www.wecc.biz (accessed on 17 April 2021).

19. Zhao, W.; Guo, Q.; Sun, H.; Ge, H.; Li, H. Practical short-term voltage stability index based on voltage curves: Definition, verification and case studies. IET Gener. Transm. Distrib. 2018, 12, 4292-4300. [CrossRef]

20. Costa, F.B.; Driesen, J. Assessment of Voltage Sag Indices Based on Scaling and Wavelet Coefficient Energy Analysis. IEEE Trans. Power Deliv. 2012, 28, 336-346. [CrossRef]

21. Ratra, S.; Tiwari, R.; Niazi, K.R. Voltage stability assessment in power systems using line voltage stability index. Comput. Electr. Eng. 2018, 70, 199-211. [CrossRef]

22. Shen, C.-C.; Lu, C.-N. A Voltage Sag Index Considering Compatibility Between Equipment and Supply. IEEE Trans. Power Deliv. 2007, 22, 996-1002. [CrossRef]

23. Kamel, M.M.M.; Karrar, A.A.; Eltom, A.H. Development and Application of a New Voltage Stability Index for On-Line Monitoring and Shedding. IEEE Trans. Power Syst. 2018, 33, 1231-1241. [CrossRef]

24. Sekine, Y.; Ohtsuki, H. Cascaded voltage collapse. IEEE Trans. Power Syst. 1990, 5, 250-256. [CrossRef] 